\title{
Tahap Kebolehan Pelajar Mendefinisikan Patriotisme Melalui Pengajaran Novel Leftenan Adnan Wira Bangsa
}

\author{
${ }^{1}$ Saripah Dora Ismail, ${ }^{2}$ Azhar Wahid \\ ${ }^{1}$ Sekolah Menangah Bukit Sentosa, 48300 Rawang, Selangor. \\ ${ }^{2}$ Fakulti Bahasa dan Komunikasi, Universiti Pendidikan Sultan Idris, Tanjong Malim, Perak.

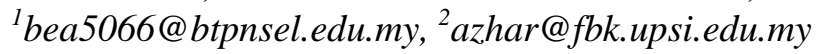

Received: 12 March 2020; Accepted: 04 December 2020; Published: 31 December 2020

To cite this article (APA): Ismail, S. D., \& Wahid, A. (2020). Tahap Kebolehan Pelajar Mendefinisikan Patriotisme Melalui Pengajaran Novel Leftenan Adnan Wira Bangsa. Jurnal Peradaban Melayu, 15, 59-68. https://doi.org/10.37134/peradaban.vol15.6.2020

To link to this article: https://doi.org/10.37134/peradaban.vol15.6.2020

\begin{abstract}
ABSTRAK
Kajian berkaitan Tahap Kebolehan Pelajar Mendefinisikan Patriotisme melalui Pengajaran Novel Leftenan Adnan Wira Bangsa ini bertujuan menilai kebolehan pelajar mendefinisikan patriotisme dengan tepat melalui pengajaran novel Leftenan Adnan Wira Bangsa yang menjadi teks kajian novel pelajar tingkatan empat. Kajian ini dibuat melalui penilaian di dalam kelas. Kajian ini juga bertujuan menguji Teori Teksdealisme terhadap novel yang dikaji. Reka bentuk kuantitatif digunakan untuk mendapatkan data penilaian berstruktur di dalam kelas. Instrumen kajian digunakan iaitu teks novel yang dikaji, set soalan dan rekod anekdot yang telah disemak oleh pakar untuk tujuan kesahan serta kebolehpercayaan. Pemilihan subjek kajian dijalankan secara persampelan kebarangkalian melibatkan 35 orang responden yang terdiri daripada pelajar tingkatan empat di Sekolah Menengah Kebangsaan Bukit Sentosa, Selangor. Penilaian pra dan pasca pengajaran yang dibuat adalah berdasarkan Model Penilaian Formatif Tessmer (1993). Data kajian dianalisis dengan menggunakan analisis teks anekdot yang dijalankan semasa penilaian pra dan pasca dilakukan. Dapatan kajian menunjukkan pelajar mampu mendefinisikan 'patriotisme' dengan lebih tepat setelah mempelajari novel ini. Kesimpulannya, novel Leftenan Adnan Wira Bangsa merupakan sebuah novel yang dikarang oleh penulis yang ideal kerana mempunyai banyak unsur patriotisme dan mampu melahirkan pelajar yang boleh menjelaskan makna patriostisme dengan tepat. Implikasi kajian menunjukkan bahawa penggunaan novel ini dapat menjadikan proses menyemai rasa patriotik dalam diri pelajar selaku pembaca menjadi lebih pantas serta relevan.
\end{abstract}

Kata kunci: Patriotisme, Novel, Leftenan Adnan Wira Bangsa

\section{PENDAHULUAN}

Seharusnya kesedaran tentang kecintaan terhadap tanah air ditanam sejak dari zaman kanak-kanak dan remaja lagi. Perasaan cinta terhadap negara dikenali sebagai patriotisme yang membawa maksud cinta dan sayang kepada negara. Pembudayaan semangat patriotik terhadap Malaysia yang merupakan negara berdaulat lazimnya dizahirkan melalui pelbagai sambutan, keraian dan perbuatan sebagai lambang cintakan negara ini oleh segenap lapisan rakyatnya. Di Malaysia umumnya, tahap kesedaran dan penghayatan semangat patriotisme akan ditonjolkan oleh rakyat sepanjang bulan Ogos memandangkan hari kemerdekaan negara yang jatuh pada 31 Ogos. Oleh sebab itulah pihak Kementerian Pendidikan Malaysia telah memilih novel Leftenan Adnan Wira Bangsa untuk dikaji oleh pelajar tingkatan empat sebagai novel kajian Komponan Sastera (KOMSAS) agar pelajar dapat memahami erti patriotisme bukan hanya pada bulan Ogos sahaja, malah diamalkan setiap masa oleh warganya.

Dalam konteks kajian ini, patriotisme bermaksud keadaan rakyat yang amat setia kepada negaranya dan sanggup melakukan apa sahaja demi pertahankan negara dari sebarang ancaman. Patriotisme dapat 
difahami konsepnya melalui pembacaan rakyat terhadap buku berunsur patriotik sejak dari bangku sekolah. Daniel Bar Tal dan Ervin Staub (1997) mentakrifkan patriotisme ini membawa maksud kesetiaan terhadap seseorang rakyat yang bermastautin di sesebuah negara yang menjadi tanah tumpah darahnya. Menurut Kamus Dewan Edisi Keempat (2004) perkataan patriotisme bermaksud keadaan cinta yang kuat pada tanah air. Manakala menurut Naffi Mat (2012), patriotisme dianggap sebagai saudara kembar nasionalisme, yang disamakan dengan tindakan pengorbanan daripada rakyat untuk membebaskan negara, kedaulatan dan memantapkan negara bangsanya. Jelaslah di sini, setiap individu perlu bersedia untuk mempertahankan kedaulatan negara dari diceroboh, dicemuh dan diancam oleh mereka yang tidak bertanggungjawab. Semangat patriotisme ini telah lama wujud dalam diri setiap individu. Dalam membicarakan isu patriotisme, pandangan Naffi Mat (2012) menyatakan, patriotisme telah lama wujud dalam peradaban manusia individu mempunyai semangat juang untuk berusaha tampil di depan masyarakat bagi mencapai hasrat yang difikirkan untuk kepentingan bersama.

Nilai patriotik dalam kajian lepas menemui dapatan bahawa semangat patriotisme yang ada di sini telahpun bermula bermula sejak dari Zaman Kegemilangan Kerajaan Melaka dan diteruskan sehingga kini (Abdul Latif Abu Bakar, 1996). Pada pandangan pengkaji lain pula, Mohd Rosli Saluddin (2012), menjelaskan bahawa fahaman membangkitkan semangat patriotisme perlu ada dalam diri setiap individu. Seharusnya fahaman ini dididik dalam jiwa anak-anak sejak dari kecil supaya mereka tahu erti patriotisme yang sebenar. Setelah itu, mereka akan meneruskan legasi masyarakat yang tahu menghargai kepentingan negara dengan meletakkan perihal kecintaan terhadap negara lebih utama berbanding dengan kepentingan diri sendiri. Generasi seperti inilah yang akan mewarisi kepemimpinan yang cemerlang dengan memastikan negara ditadbir urus dengan baik untuk menunjukkan kasih sayang mereka terhadap negara.

Pemilihan novel Leftenan Adnan Wira Bangsa untuk aspek kajian pelajar dilihat sesuai memandangkan Leftenan Adnan merupakan salah seorang askar yang berjiwa patriotik (Nik Anuar Nik Mahmud et al., 2011). Beliau yang merupakan anak sulung daripada tiga adik-beradik lelaki. Beliau dilahirkan di Sungai Ramal, Kajang Selangor pada 1915. Walaupun Adnan dihantar ke sekolah beraliran Inggeris, namun semangat patriotik tidak pernah luntur dalam diri beliau. Darah keturunan kepahlawanan yang mengalir di dalam diri Adnan juga menjadikan beliau amat berminat untuk menyertai pasukan askar meskipun ibu bapanya berharap agar Adnan menjadi seorang pendidik di samping seorang anak yang soleh yang boleh berbakti kepada bangsa, agama dan negara.

Melihat kepada kesungguhan Adnan yang ingin menceburkan diri dalam bidang ketenteraan, ibu bapanya menyokong keputusan Adnan untuk berkhidmat sebagai askar yang sentiasa bersiap siaga mempertahankan negara. Sesungguhnya kisah hidup Adnan yang digambarkan dalam novel memainkan peranan yang penting dalam membina pengetahuan awal pelajar terhadap patriotisme sejak dari bangku sekolah lagi. Hal ini selari dengan aspirasi pihak Kementerian Pendidikan Malaysia iaitu menjadikan pembelajaran sebagai medium yang berkesan untuk membentuk pelajar yang dapat menerapkan nilai patriotik dalam diri mereka.

\section{OBJEKTIF}

Objektif kajian Tahap Kebolehan Pelajar Mendefinisikan Patriotisme melalui Pengajaran Novel Leftenan Adnan Wira Bangsa ini adalah untuk:

i. Menilai penjelasan pelajar tentang patriotisme melalui pembacaan novel Leftenan Adnan Wira Bangsa.

ii. Menjelaskan definisi patriotisme berdasarkan kajian tahap kebolehan pelajar mendefinisikan patriotisme melalui pengajaran novel Leftenan Adnan Wira Bangsa. 


\section{METODOLOGI}

Kajian Tahap Kebolehan Pelajar Mendefinisikan Patriotisme dijalankan melalui reka bentuk kuantitatif iaitu dengan memfokuskan kepada pengumpulan data primer iaitu penilaian berstruktur di dalam kelas. Penilaian ini dijalankan berdasarkan Model Penilaian Formatif Tessmer yang diubah suai melibatkan empat peringkat utama. Peringkat-peringkat ini melibatkan penilaian pakar yang terdiri daripada mereka yang arif dalam bidang kajian, penilaian responden secara individu, penilaian dalam kumpulan kecil dan akhir sekali berulah penilaian kajian sebenar dilakukan. Pengumpulan data melibatkan penilaian yang dilakukan sebelum dan selepas pengajaran aspek novel di dalam kelas selaras dengan model yang digunakan iaitu Model Penilaian Formatif Tessmer. Instrumen yang digunakan untuk mengumpulkan data dalam kajian ini adalah set soalan dan rekod anekdot untuk menilai tahap kebolehan pelajar. Penilaian berstruktur di dalam kelas ini dapat mengumpulkan maklumat tahap kebolehan pelajar menjawab soalan yang dikemukakan oleh guru sebelum dan selepas pengajaran aspek novel dalam kelas. Aspek penilaian setelah pelajar menjawab soalan akan direkodkan dan dinilai pencapaian markah mereka. Seterusnya markah-markah ini akan dikelaskan dalam tiga tahap iaitu telah menguasai, sedang maju dan belum menguasai.

Bagi menjalankan penilaian berstruktur, subjek kajian dipilih berdasarkan teknik persampelan kebarangkalian yang melibatkan 35 orang pelajar tingkatan empat di SMK Bukit Sentosa. Pelajar yang dipilih adalah pelajar yang telah membaca keseluruhan teks novel Leftenan Adnan Wira Bangsa. Sampel pelajar yang terpilih ini diterangkan arahan yang perlu mereka lakukan sebelum penilaian dijalankan secara berterusan bagi melihat perkembangan pelajar dalam proses pembelajaran aspek novel yang dijalankan di dalam kelas. Kaedah penilaian berdasarkan kepada Model Penilaian Formatif Tessmer secara berstruktur di dalam kelas bagi menilai kebolehan pelajar mendefinisikan maksud patriotisme dengan tepat.

Dalam penilaian berdasarkan Model Penilaian Formatif Tessmer yang dibuat terhadap sampel iaitu seramai 35 orang pelajar ini, pengkaji melakukan empat peringkat penilaian formatif terhadap sampel yang terlibat. Peringkat yang disebutkan adalah seperti berikut:

i. Peringkat penilaian pakar

ii. Peringkat penilaian satu persatu

iii. Peringkat penilaian kumpulan kecil

iv. Peringkat penilaian sebenar

Rajah model yang digunakan dalam kajian ini telah diadaptasi daripada Model Penilaian Formatif Tessmer (1993) dan ditunjukkan dalam Rajah 1. 


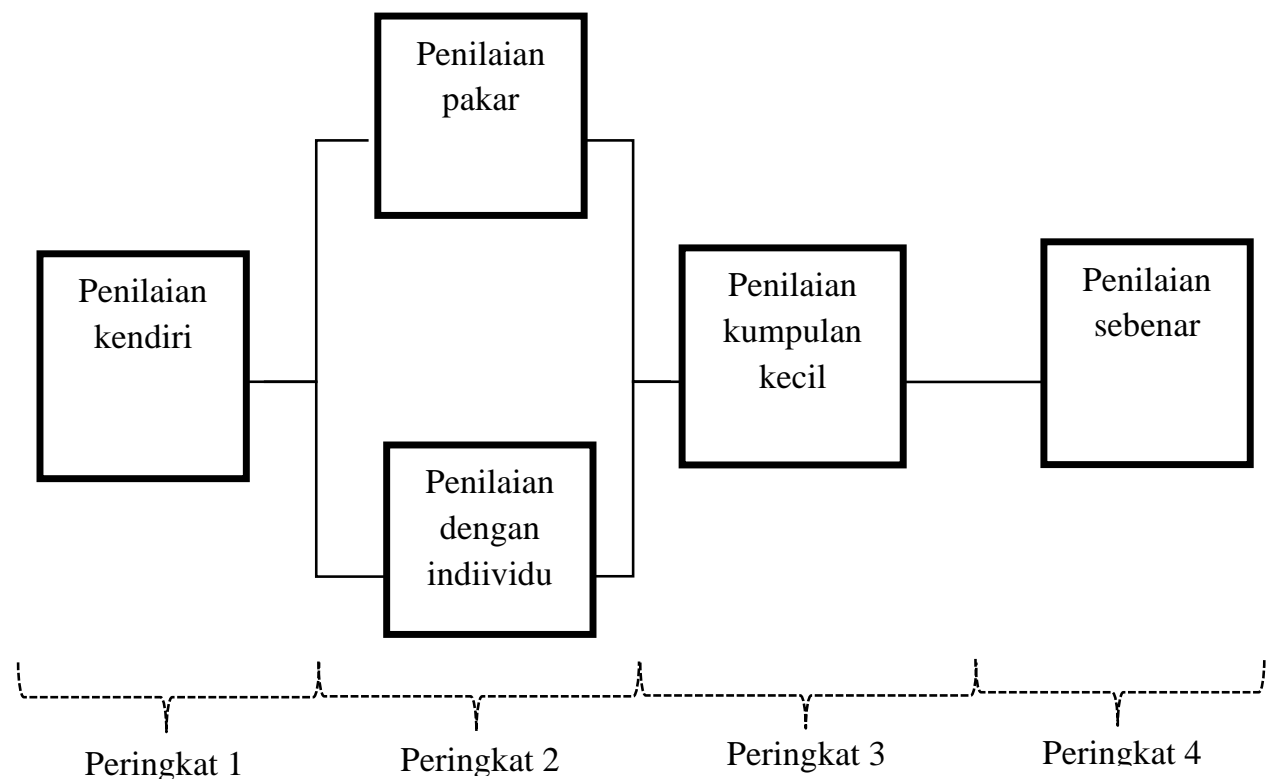

Rajah 1 Model Penilaian Formatif. Ubah suai daripada Model Penilaian Formatif Tessmer (1993).

Peringkat pertama, pengkaji membina instrumen penilaian dalam kelas iaitu senarai semak dan rekod anekdot yang sesuai. Semakan pakar menentukan sama ada instrumen yang dibuat menepati ciri instrumen penilaian seperti garis panduan pembinaan instrumen penilaian formatif, iaitu dapat mengukur pengetahuan dan kemahiran yang dijangka serta tingkah laku pelajar yang ditunjukkan oleh sampel. Peringkat kedua juga melibatkan penilaian dengan seorang sampel iaitu pelajar menjawab soalan yang dikemukakan oleh guru. Guru kemudiannya melihat serta menilai sama ada penilaian formatif ini sesuai dijalankan atau tidak.

Penilaian formatif dengan seorang pelajar memerlukan pengkaji terangkan maklumat pengajaran yang akan diajarkan dan objektif pengajaran. Pengkaji juga perlu memastikan aras kesesuaian soalan dan kesannya kepada pelajar selepas sesi pengajaran dilakukan (Tessmer, 1993). Pada peringkat ketiga, penilaian dilakukan melibatkan kumpulan kecil iaitu seramai tiga orang pelajar dinilai dan seterusnya penilaian sebenar di dalam kelas yang melibatkan seluruh sampel yang terpilih. Dalam kajian ini penilaian sebenar melibatkan dua sesi memandangkan ramai sampel yang terlibat untuk penilaian iaitu seramai 35 orang pelajar.

Pengkaji melakukan penilaian terhadap sampel sebelum pengajaran novel diajar di dalam kelas secara formal. Pengkaji akan meminta sampel menjawab soalan yang dikemukakan oleh guru berdasarkan kepada pengetahuan sedia ada setelah mereka membaca teks ini dari awal sehingga tamat ceritanya. Guru kemudiannya akan mengajar aspek kajian berkaitan novel dan sekali lagi penilaian dijalankan dengan menyoal beberapa soalan untuk dijawab oleh mereka. Dalam kedua-dua sesi ini, jangka masa yang diambil oleh sampel untuk menjawab, keyakinan diri, dan penilaian jawapan akan direkodkan oleh pengkaji untuk dianalisis secara korelasi dapatan data menggunakan prosedur SPSS.

Melalui analisis korelasi yang dilakukan, pengkaji akan dapat gambaran sebenar bagaimana proses pengajaran dan pembelajaran aspek novel ini mampu mengukur dan menilai tahap kebolehan pelajar definisikan patriotisme dengan makna yang tepat berdasarkan pra dan pasca pengajaran novel. Hasil analisis korelasi ini dapat menjawab objektif kajian sama ada tercapai atau tidak iaitu menilai kemampuan pelajar dalam menjelaskan makna patriotisme melalui pembelajaran novel Leftenan Adnan Wira Bangsa dan kebolehan menjelaskan definisi patriotisme berdasarkan pengajaran novel Leftenan Adnan Wira Bangsa. 
Sebelum pengajaran aspek novel di dalam kelas, pengkaji telah menyoal mereka dalam masa 10 hingga 15 minit. Pelajar akan disoal dan diperhatikan perkembangan mereka dalam aspek bahasa dan literasi, keyakinan diri, interaksi secara bersemuka dan kemahiran menyelesaikan soalan yang dikemukakan. Pelajar-pelajar ini merupakan pelajar yang telah membaca keseluruhan novel. Soalan yang ditanya seperti Jadual 1 berikut:

Jadual 1 Soalan yang dikemukakan kepada pelajar untuk penilaian di dalam kelas.

\begin{tabular}{ll}
\hline Bil & Soalan \\
\hline 1. & Adakah anda telah membaca keseluruhan novel Leftenan Adnan Wira Bangsa? \\
2. & Siapakah watak utama novel tersebut? \\
3. & Apakah nilai utama yang ditonjolkan oleh watak utama? \\
4. & Adakah anda faham maksud patriotisme? Huraikan. \\
5. & Bolehkan anda terangkan apa peranan anda untuk mempraktikkan patriotisme dalam \\
& $\quad$ kehidupan anda kini? \\
\hline
\end{tabular}

Dapatan penilaian di dalam kelas ini direkodkan dalam dokumen instrumen rekod anekdot. Rekod anekdot yang digunakan sebagai instrumen kajian telah mendapat kesahan muka oleh pakar bagi membolehkan pengkaji mengumpulkan dapatan untuk dianalisis. Penulisan rekod yang berkesan dalam setiap penilaian yang dibuat amat berkesan sebagai alat pengukur kajian kerana dapat mendokumentasikan kajian dan peristiwa dengan jelas serta tepat setelah mengikut panduan yang ditetapkan. Terdapat beberapa panduan yang perlu dipatuhi oleh pengkaji sepanjang melakukan kajian menggunakan rekod anekdot sebagai bahan instrumen kajian mereka. Pengkaji yang patuh pada panduan ini berupaya untuk mendapatkan dapatan yang jitu dan tekal. Panduan yang perlu diikuti oleh pengkaji semasa menggunakan rekod anekdot dalam kajian mereka ini adalah seperti Jadual 2.

Jadual 2 Panduan semasa menggunakan rekod anekdot.

\begin{tabular}{ll}
\hline Bil & Panduan penggunaan rekod anekdot \\
\hline 1. & Menilai segala tingkah laku yang terjadi. \\
2. & Menggunakan rekod anekdot piawai. \\
3. & Merekod perkara sebenar yang dinilai. \\
4. & Menggunakan pencapaian bagi terangkan dapatan. \\
5. & Berhati-hati memasukkan maklumat pelajar terlibat. \\
6. & Menyedari ahli profesioanal lain juga dapat peroleh maklumat \\
\hline Sumber: diubah suai daripada A. Ghani Abdullah, (2009)
\end{tabular}

Ujian formatif yang dijalankan ini merupakan ujian untuk mendapatkan maklumat berkait dengan tahap pemahaman makna patriotisme dalam kalangan pelajar. Pengujian dilakukan terhadap pelajar menerusi ujian rujukan kriteria patriostime dan tahap pencapaian mereka dikelaskan sama ada telah menguasai, sedang maju dan belum menguasai konstruk yang diukur. Hasil dapatan sepanjang dikaji akan dicatatkan dalam borang rekod anekdot untuk dianalisis melalui analisis dokumen dan kemudiannya dianalisis menerusi perisian SPSS.

\section{POPULASI DAN PENSAMPELAN}

Bagi penilaian formatif menerusi pra dan pasca pengajaran dalam kelas, populasi sampel melibatkan keseluruhan bilangan pelajar Tingkatan Empat Komoditi dari Sekolah Menengah Kebangsaan Bukit Sentosa, Daerah Hulu Selangor iaitu seramai 35 orang pelajar. Pensampelan pula merupakan subset atau sebahagian tertentu populasi yang terlibat dalam kajian. Perkara ini bermaksud pensampelan 
adalah kaedah pengkaji dapatkan maklumat untuk selesaikan masalah tanpa menggunakan jumlah keseluruhan populasi (Ghazali \& Sufean, 2016). Pensampelan yang dipilih dalam kajian ini adalah pensampelan kebarangkalian iaitu setiap populasi yang dipilih mempunyai kebarangkalian yang sama untuk dipilih. Enrolmen 35 orang pelajar yang terlibat dalam penilaian ini adalah seperti Jadual 3.

Jadual 3 Enrolmen pelajar tingkatan 4 yang terlibat dalam penilaian guru.

\begin{tabular}{llllc}
\hline Bil & Kaum & Lelaki & Perempuan & Peratus $(\%)$ \\
\hline 1 & Melayu & 14 & 8 & 62.86 \\
2 & Cina & 2 & 2 & 11.43 \\
3 & India & 5 & 2 & 20.00 \\
4 & Orang Asli & 1 & 1 & 5.71 \\
\hline \hline & JUMLAH & 22 & 13 & 100.00 \\
\hline
\end{tabular}

\section{DAPATAN KAJIAN}

Penilaian yang dibuat terhadap sampel pelajar berdasarkan Model Penilaian Formatif Tessmer melibatkan lima kriteria utama iaitu keyakinan diri pelajar, penguasaan bahasa, mengenali watak utama, mendefinisikan makna patriotisme dengan tepat dan kesediaan pelajar mempraktikkan amalan patriotik. Dapatan yang diperoleh pengkaji awalnya mendapati dalam masa 10 minit pelajar melakukan komunikasi dua hala dengan guru, seramai lima orang (54.3\%) pelajar tidak yakin menjawab soalan yang dikemukakan oleh guru. Hanya 19 orang (54.3\%) yang menunjukkan tahap keyakinan diri yang agak baik. Mereka banyak menundukkan muka ke bawah. Keyakinan mereka terhadap jawapan yang diberikan juga amat rendah dan 11 orang sedang cuba untuk meningkatkan keyakinan diri. Mereka teragak-agak semasa menjawab.

Dalam aspek bahasa pula, kelancaran bahasa mereka tidak lancar dan tersekat-sekat. Daripada 35 orang pelajar, hanya 8 orang $(22.9 \%)$ pelajar yang mampu berkomunikasi dengan baik dan menggunakan tatabahasa yang betul semasa bercakap. Seramai 6 orang $(17.1 \%)$ pelajar banyak menggunakan bahasa pasar iaitu bahasa percakapan mereka seharian manakala 21 orang $(60.0 \%)$ menguasai sebahagian daripada aspek bahasa semasa menjawab. Walaupun begitu, seramai 28 orang $(80.0 \%)$ pelajar dapat menjelaskan watak utama novel dengan baik iaitu 'Leftenan Adnan' manakala tujuh orang (20.0\%) lagi menjawab nama watak utama yang salah.

Dalam aspek makna pendefinisian 'patriotisme' pula, semua 35 orang pelajar (100.0\%) tidak dapat memberikan makna yang tepat terhadap definisi patriotisme yang guru kemukakan dengan tepat. Pelajar menjawab bahawa patriotisme bermaksud 'sayang pada negara', 'menyayangi negara', 'cintakan negara kita' dan 'mencintai negara dan tiada penjajahan'. Seramai tiga (8.6\%) pelajar lagi tidak menjawab dan hanya menggelenggkan kepala dan hanya tersenyum apabila ditanya.

Guru kemudiannya meminta pelajar menyatakan peranan mereka mempraktikkan patriotisme pada masa ini. Sumbang saran dilakukan supaya pelajar aktif menjawab. Seramai 31 orang $(88.6 \%)$ pelajar berada pada tahap sedang maju apabila mereka mengemukakan jawapan 'mereka akan sayangi negara dengan bersungguh-sungguh', 'tidak terlibat dalam kegiatan yang merosakkan negara', 'mengelakkan pertumpahan darah antara kaum', dan 'mengajak rakan-rakan yang lain menyayangi negara kita.' Jawapan pelajar lain yang diberikan adalah lebih kurang sama dengan yang dinyatakan. Hal ini menunjukkan pelajar belum bersedia untuk mempraktikkan nilai dan unsur patriotisme dalam kehidupan kini.

Guru kemudiannya mengajarkan tajuk berkaitan novel iaitu subtopik watak dan perwatakan, nilai dan pengajaran kepada mereka selama 30 minit yang seterusnya. Pelajar kemudian ditanya soalan yang sama terhadap mereka. Pemerhatian kedua dilakukan dan dicatatkan oleh guru dalam borang rekod 
anekdot. Dalam penilaian ini, guru dapati mereka dapat menjawab soalan yang dikemukakan dengan lebih pantas dan keyakinan mereka semasa menjawab soalan yang dikemukakan oleh guru juga meningkat kepada $82.9 \%$ iaitu seramai 29 orang pelajar yang lebih berkeyakinan menjawabnya. Pelajar tidak lagi menunduk semasa menjawab soalan yang dikemukakan. Malah mereka lebih berani bertentang mata dengan guru semasa menjawab. Hanya seorang pelajar (2.9\%) yang dilihat agak malu untuk menyatakan jawapan semasa berkomunikasi dengan guru.

Penguasaan bahasa juga semakin baik apabila pelajar ini telah diberitahu bahawa jawapan mereka dinilai dalam aspek tatabahasa, nada dan intonasi semasa mengemukakan jawapan. Dapatan menunjukkan seramai 25 orang $(71.4 \%)$ pelajar yang menggunakan laras bahasa dengan baik manakala lima orang pelajar (14.3\%) masih sedang maju dan belum kuasai aspek bahasa dengan baik. Mereka ini terdiri daripada pelajar yang bukan berbangsa Melayu. Lebih membanggakan apabila keseluruhan pelajar dapat mengenali watak utama yang terdapat di dalam novel iaitu 'Leftenan Adnan'.

Seramai 33 orang (94.3\%) pelajar juga dapat mendefinisikan 'patriotisme' dengan baik dan lebih tepat iaitu patriotisme bermaksud 'sifat yang dimiliki oleh seseorang yang sayang akan negara mereka dan sanggup melakukan apa sahaja untuk negaranya' dan 'perasaan yang perlu ada dalam diri seorang rakyat sesebuah negara untuk bekorban apa sahaja demi negaranya.' Selebihnya iaitu dua orang $(5.8 \%)$ tidak mampu mendefinisikan patriotisme dengan tepat.

Dalam masa yang sama pelajar juga dapat mengaitkan topik patriotisme dengan kesediaan mereka mempraktikkan amalan patriotisme. Seramai 34 orang $(97.1 \%)$ pelajar yang berupaya mengungkapkan kesediaan mereka mempraktikkan amalan dan nilai patriotisme dalam kehidupan seharian kini dan seorang lagi berada pada peringkat sedang maju memandangkan pelajar ini juga yang belum menguasai definisi patriotisme dengan tepat.

Dapatan pemerhatian menerusi rekod anekdot dijelaskan dalam Jadual 4 dan dianalisis dengan menggunakan perisian SPSS analisis korelasi bagi menentukan tahap kebolehan pelajar mendefinisiskan patriotisme sebelum dan selepas pengajaran aspek novel dijalankan di dalam kelas mereka.

Jadual 4 Analisis rekod anekdot pra dan pasca pengajaran di dalam kelas.

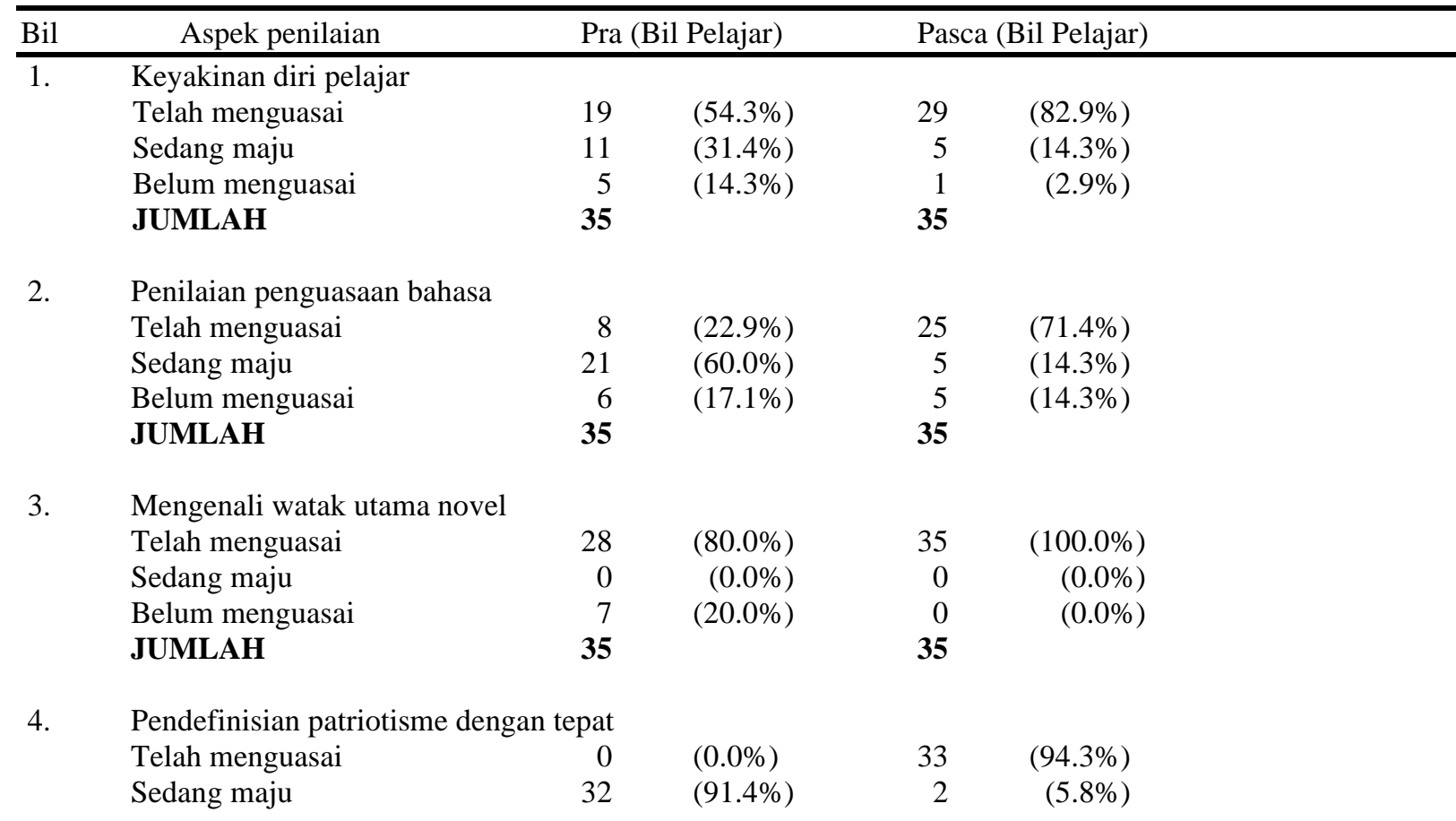




\begin{tabular}{|c|c|c|c|c|}
\hline Belum menguasai & 3 & $(8.6 \%)$ & 0 & $(0.0 \%)$ \\
\hline JUMLAH & 35 & & 35 & \\
\hline \multicolumn{5}{|c|}{ Kesediaan pelajar praktikkan amalan patriotik } \\
\hline Telah menguasai & 0 & $(0.0 \%)$ & 34 & $(97.1 \%)$ \\
\hline Sedang maju & 31 & $(88.6 \%)$ & 1 & $(2.0 \%)$ \\
\hline Belum menguasai & 4 & $(11.4 \%)$ & 0 & $(0.0 \%)$ \\
\hline JUMLAH & 35 & & 35 & \\
\hline
\end{tabular}

Sumber: Kajian soal selidik

Berdasarkan Jadual 5 yang diperoleh menerusi penilaian dalam kelas, analisis aplikasi korelasi Pearson dibuat bagi menentukan kesan pengajaran novel Leftenan Adnan Wira Bangsa terhadap kebolehan pelajar mendefinisiskan patriotisme. Bagi menentukan tahap kebolehpercayaan sesuatu kajian yang dibuat, nilai Cronbach's Alpha digunakan. Menurut Sekaran (2003), nilai Cronbach's Alpha yang terbaik adalah $>0.8$. Nilai Cronbach's Alpha 0.6 hingga 0.8 pula bermaksud munasabah tahap kebolehpercayaannya dan nilai Cronbach's Alpha $<0.6$ adalah rendah dan tidak boleh diterima dalam sesuatu kajian yang dijalankan.

Dalam kajian ini, nilai Cronbach's Alpha yang diperoleh adalah 0.7 iaitu dalam lingkungan nilai kebolehpercayaan yang boleh diterima dan munasabah untuk dipercayai bagi setiap responden iaitu pelajar yang terlibat dalam kajian pemerhatian ini. Hal ini ditunjukkan dalam Jadual 5.

Jadual 5 Nilai kebolehpercayaan Cronbach's Alpha.

\begin{tabular}{|l|r|r|}
\hline Cronbach's Alpha & $\begin{array}{c}\text { Cronbach's Alpha berdasarkan } \\
\text { standard item }\end{array}$ & N (Items) \\
\hline .776 & .797 & \\
\hline
\end{tabular}

Untuk menentukan kekuatan hubungan antara penulisan teks yang mematuhi keempat-empat prinsip dalam penulisan Teori Teksdeealisme dan kebolehan pelajar mendefinisikan patriotisme dengan tepat, pekali korelasi digunakan. Pekali korelasi menurut Fauzi Hussin (2014) merupakan suatu indeks yang menunjukkan tahap hubungan antara pemboleh ubah kajian. Jadual 6 menunjukkan nilai analisis antara 0.00 hingga 1.00 yang menunjukkan kekuatan sesuatu hubungan yang dgunakan oleh pengkaji.

Jadual 6 Interpretasi Nilai Pekali Korelasi.

\begin{tabular}{ll}
\hline Nilai pekali & Tahap Hubungan \\
\hline 1.0 & Sempurna \\
$0.80-0.99$ & Sangat Kuat \\
$0.60-0.79$ & Kuat \\
$0.40-0.59$ & Sederhana \\
$0.20-0.39$ & Lemah \\
$0.01-0.19$ & Sangat Lemah \\
0.0 & Tiada Hubungan \\
\hline Sumber: Fauzi Hussin (2014) &
\end{tabular}

Hubungan antara kebolehan pelajar mendefinisikan patriotisme dengan tepat semasa pra $(M=1.06$, $\mathrm{SD}=0.24)$ dan pasca pengajaran $(\mathrm{M}=2.08, \mathrm{SD}=0.28)$ dianalisis berdasarkan dapatan bil. 4 dalam jadual 4.7. Analisis korelasi menunjukkan hubungan positif yang sangat kuat dan signifikan pada nilai pekali $(\mathrm{r}=0.80)$ Hal ini menunjukkan tahap kebolehan pelajar mendefinisikan makna patriotisme dengan tepat adalah signifikan dengan pasca pengajaran aspek novel oleh pelajar. Hal ini didasari oleh kekuatan novel Leftenan Adnan Wira Bangsa yang berupaya menunjukkan sifat idealnya sehingga memberikan 
kesan yang positif terhdap pembacaan pelajar. Hasil ini selaras dengan Teori Teksdealisme yang berupaya menjadikan novel ini memberikan impak kepada pembaca dan seterusnya dapat pengaruhi peningkatan pencapaian 35 orang pelajar memahami makna patriotisme ketika pasca pengajaran dijalankan. Hasil kajian ini dapat mengukur kebolehan pelajar mendefinisikan makna patriotisme dengan lebih tepat. Analisis dapatan korelasi seperti Jadual 7.

Jadual 7 Korelasi antara pengajaran novel dengan kebolehan pelajar mendefinisi patriotism.

\begin{tabular}{lll}
\hline & \multicolumn{2}{c}{ Pencapaian Pelajar } \\
Kriteria & \multicolumn{2}{c}{ Pra } \\
\hline Pearson Correlation & 1.0 & $0.80^{* *}$ \\
Sig. (2-tailed) & 0.00 & 0.00 \\
$\mathrm{~N}$ & 35 & 35 \\
\hline$* *$ Korelasi signifikan pada aras keertian, $p=0.01$ & &
\end{tabular}

Berdasarkan analisis korelasi yang dibuat seperti dalam Jadual 7, analisis menunjukkan wujud satu hubungan positif yang sangat kuat iaitu $\mathrm{r}=0.80$ dan signifikan $\mathrm{p}(=0.00<0.01)$ antara penilaian pra dan pasca yang didapati daripada pemerhatian yang dijalankan di dalam kelas. Hal ini juga bermakna, ketika pra penilaian dilakukan, pelajar ramai yang berada pada tahap sedang maju dan setelah diajarkan aspek novel terhadap pelajar tahap kemajuan pelajar tersebut mencapai tahap menguasai dalam penilaian pasca adalah sangat kuat.

Hal ini juga didasari oleh pematuhan penulisan teks yang mempunyai ciri-ciri keunggulan dan ideal sehingga berupaya meletakkan teks Leftenan Adnan Wira Bangsa ini sebagai teks yang bermutu. Teks novel ini selayaknya diketegorikan teks yang bermutu kerana dapat memberikan kesan yang ideal kepada pembacanya. Keunggulan teks ini dapat dibuktikan melalui hubungan positif yang sangat kuat dan signifikan dengan kemajuan pelajar mengungkapkan makna patriotisme dengan tepat.

\section{KESIMPULAN}

Berdasarkan kajian yang telah dilakukan, pengajaran novel Leftenan Adnan Wira Bangsa berupaya untuk melahirkan pelajar yang mampu mendefinisikan patriotisme dengan tepat. Hubungan antara kebolehan pelajar mendefinisikan patriotisme dengan pengajaran novel Leftenan Adnan Wira Bangsa adalah signifikan. Pengkaji juga dapati bahawa penulis novel mempunyai kepakaran penulisan yang tinggi kerana berjaya menghasilkan sebuah novel sejarah yang hebat dan sarat dengan peristiwa yang menonjolkan semangat patriotisme tokoh pejuang yang bernama Adnan bin Saidi dalam perjuangan mempertahankan maruah bangsa dan tanah air tercinta sehinggakan novel tulisan beliau mampu meninggalkan kesan yang baik kepada pembacanya.

\section{RUJUKAN}

A. Ghani Abdullah. (2009). Mengurus Tingkah Laku Pelajar. Kuala Lumpur: PTS Profesional.

A. Halim Ali, Mana Sikana \& Mohd Rosli Saludin. (2011). Prosiding Sastera Membina Peradaban Bangsa. Budiman Malaysia.

Abdul Lafiff Abu Bakar. (1996). Konsep Patriotisme dan Nasionalisme. Kuala Lumpur: Penerbit Universiti Malaya.

Abdul Latip Talib. (2008). Leftenan Adnan Wira Bangsa. Kuala Lumpur: PTS Publication \& Distributors Sdn. Bhd.

Abdul Rahman Abdul Aziz. (2014). Isi-Isi Ketahanan Nasional. Kuala Lumpur: Institut Terjemahan Buku Malaysia Sdn. Bhd. 
Abdul Rahman Napiah. (2013). Berdiri di Akar Diri: Kritikan Sastera Melayu Pasca Moden. Kuala Lumpur: Institut Terjemahan dan Buku Malaysia Berhad.

Azizi Yahya, Shahrin Hashim, Jamaludin Ramli, Yusof Boon \& Abdul Rahim Hamdan. (2006). Menguasai Penyelidikan Dalam Pendidikan: Teori, Analisis \& Interpretasi Data. Kuala Lumpur: PTS Profesional.

Babbie E. (2010). The Practice of Social Research. Amarika Syarikat: Wadsworth Cengage Learning.

Bhasah Abu Bakar. (2007). Kaedah Analisis Data Penyelidikan Ilmiah. Kuala Lumpur: Utusan Publication \& Distributors Sdn. Bhd.

Creswell, J. W. (2003). Research Design: Qualitative, Quantitative and Mix Methods Approaches. London: Sage Publications.

Daniel Bar Tal dan Ervin Staub. (1997). Patriotism in the Lives of Individuals and Nations. Amarika Syarikat: Nelson.

Fauzi Hussin. (2014). Kaedah Penyelidikan \& Analisis Data SPSS. Sintok: Penerbit Universiti Utara Malaysia.

Kamus Dewan Edisi Keempat. (2004). Kuala Lumpur: Dewan Bahasa dan Pustaka.

Mohd Rosli Saluddin, (2012). Kebangkitan Semangat Patriotisme Menentang Fahaman Komunis. (Peny. Abdul Latif Abu Bakar). Institut Peradaban Melayu. Tanjong Malim: Universiti Pendidikan Sultan Idris.

Naffi Mat, (2012). Patriotisme dalam Novel Ratab Rabitah: Perjuangan Seorang Wanita. (Peny. Abdul Latif Abu Bakar). Institut Peradaban Melayu. Tanjong Malim: Universiti Pendidikan Sultan Idris.

Nik Anuar Nik Mahmud, Muhammad Haji Salleh \& Abd. Ghapa Harun, (2011). Biografi Tun Abdul Razak: Negarawan dan Patriot. Bangi: Universiti Kebangsaan Malaysia.

Tessmer M. (1993). Planning and Conducting Formative Evaluations: Improving the Quality of Education and Training. United Kingdom: Psychology Press. 